\title{
THE ARTIFICIAL EAR AND THE DISABILITY DATA GAP
}

\begin{abstract}
A rabbit vibrating in $\mathrm{F}$
On the evening of Monday, 6 September 1886, Professor William Rutherford travelled from Edinburgh to Birmingham to deliver a lecture to the British Medical Association on a subject that he described as being on 'the borderland between the realm of physics and that of consciousness. ${ }^{1}$ He began by inviting his audience to consider the nature of sound while they listened to a vibrating pendulum and a number of differently pitched tuning forks. After this, he started on his main topic, 'The Telephone Theory of the Sense of Hearing', inspired by the invention of the telephone ten years earlier. He enthused: 'It is, indeed, one of the most wonderful inventions of recent times', and asked his audience, 'can it throw light on the sense of hearing?'. Rutherford had developed a theory of frequency transmission based on the working of the telephone and he postulated that each sound stimulated a corresponding hair cell in the ear, with a correlation between the number of hair cells and the audibility of the transmission. Rutherford had reached this conclusion by taking apart and experimenting with, variously, a telephone, a frog and a rabbit. $\mathrm{He}$ boasted: 'I could send as many as 352 impulses per second along the nerve of a rabbit and get a note from the muscle of the pitch of 352 vibrations per second. That is a note of the pitch of $\mathrm{F}$ on the lowest space of the treble clef.' ${ }^{3}$

It might not seem that a rabbit vibrating in $\mathrm{F}$ has much in common with the British Post Office. Yet not long after Rutherford's experiments, that institution was also trying to discover the extent to which the telephone could throw light on the sense of hearing. Indeed, the Post Office was soon designing telephones specifically for people with hearing loss as part of their governmentmandated state monopoly. What happened, in this short space of time, to take British telephone technology from vibrating rabbits to a telephone service for
\end{abstract}


'Deaf Subscribers'? In some ways very little, as we can see from case studies of users with hearing loss who engaged with the Post Office to improve amplified telephony. The early telephone was very difficult to hear. After failing to access telephony, users with hearing loss responded to its failings by using alternative devices, creating personalised devices or lobbying the Post Office to improve its service. Rutherford's experiments were thus emblematic of the way that the Post Office's amplified telephone service developed, that is, dependent on user experiences and individual experiments, and inextricably tied into the telephone's complicated connection to deafness.

As the Introduction to this book outlined, the telephone was linked to deafness from its 1876 conception: the result of Alexander Graham Bell's desire to teach the deaf to speak. The telephone soon evolved into a hearing testing device in the form of the early induction-coil-style audiometer, which literally commodified the telephone as a device to measure hearing loss. ${ }^{4}$ This prioritised quantitative single-number indicators of hearing loss over the qualitative data produced by tuning forks; a development which will be given further consideration in Chapter 4. Here, I argue that the telephone itself was also used as an arbitrator of normal hearing. Moreover, the data used to create a so-called normal level of hearing used in the 'artificial ear' featured what I term a 'disability data gap'. The artificial ear's representation of normal was in fact the ideal (eight normal men with good hearing), to the detriment of those at the outer edges of a more representative average curve. As a result of this, those with less than perfect hearing agitated to demand the Post Office supply telephones that could be used by the majority of the population. The Post Office responded by creating its 'telephone service for the deaf', and the subsequent user appropriation and modification of this service vividly demonstrates the fluid categorisation of deafness that the telephone enabled.

This chapter has three main sections. ${ }^{5}$ In the section below on 'The deafened', I explain the ways in which the First World War improved the technology available for use in telephony, while simultaneously creating the conditions of mass deafening that made such technology necessary. Before the First World War, noise-induced hearing loss was mainly a problem for the marginalised working class, but by the eve of the Second World War, hearing loss was regarded as a serious national health concern. This transition was caused by the First World War changing the context of hearing loss. The First World War was the first example of large-scale, industrialised deafening of soldiers. Losing hearing in the service of the country made the condition one that demanded compensation, and this became an issue for the middle and upper classes. During the interwar years the boundaries between deafness and hearing loss were blurred, and definitions depended on the cause and context of the hearing loss. 
Vast numbers of newly deafened soldiers prompted an ideological shift concerning attitudes to hearing loss, and the concept of 'the Deafened' emerged during this period as a new term used to categorise adults with hearing loss. Crucially, this kind of categorisation was linked to the way that the Post Office standardised 'normal hearing' using a device called 'the artificial ear' which used data taken from just ten 'normal' male ears. This device was designed as a way of efficiently and objectively measuring and reproducing sound quality without human involvement. This, as I argue in the section on 'The artificial ear', allowed the Post Office to manage the variability of hearing and standardise the norms of human hearing. However, it also featured a disability data gap', which meant that the standard of normal hearing was distorted to reflect an idealised average. This impacted on the standards that were used to design 'normal telephones' in Britain. If users did not have the ability to use the normal telephones, then it followed that they had to use the 'telephone service for the deaf'.

Designating the standard of normal hearing in such a narrow mechanistic fashion resulted in increased disconnect between the objective measurement of hearing and the subjective correlate. The resulting problems are discussed in the case studies in the section on 'Individual users versus institutional innovations', which forms the main part of this chapter. Here, I reveal how aspirational users employed a variety of strategies to ensure equitable access to telephony. Users with hearing loss created modified devices so that they could access telephony in a manner sympathetic to their personal experiences of hearing loss. Although the state played a key role in directing Post Office research into hearing assistive devices, the main force motivating the design of the amplified telephone was user activism. Deaf subscribers' personal bodily knowledge was turned into a product that the Post Office could sell on. Yet the interplay between the Post Office and its users was more complex than simple appropriation, especially in the 1920s, when, I argue, amplified telephone technology was in a state of 'interpretive flexibility', with its meaning not yet fixed or defined. ${ }^{6}$ That is, during the interwar years the amplified telephone was neither purely medical nor simply technical, and the boundaries between hearing loss and deafness changed with improvements to the technology.

Historian Michael Kay's study of telephone use in the nineteenth century has demonstrated that the telephone's broad inaudibility was one of the main reasons for initial widespread user rejection. ${ }^{7}$ For anyone with less than perfect hearing the telephone was inaccessible. This came as a blow to many members of the Deaf community, who had hoped that it could be used like a hearing aid. ${ }^{8}$ Subsequently, the first electronic hearing aids were indeed based on basic microphone telephone technology and were often simply called 'phones' 
or some variant thereof like 'fortiphone', 'magniphone', 'electrophone', 'ossiphone' or 'micro-telephone', or named to indicate their more specialist roles, such as 'operaphones' or 'the "lady shopper's" electric phone.' The 'phone' suffix distinguished these types of hearing aids from the valve-operated hearing aids which developed after the First World War. One man in the US did not wait for these technical developments, and simply walked with an unadorned telephone and his hearing horn attached to him, proffering the receiver to any potential conversationalists. ${ }^{10}$ These individualistic solutions were of varying effectiveness, however, and institutional resolutions were soon demanded from the Post Office.

Despite its vast institutional size, the impression historians typically garner of the interwar Post Office is of a monolithic entity with one voice, because any institutional decision had to be agreed by the London headquarters, where the Postmaster General always had the final say. Despite its narrow structure, the Post Office comprised a huge number of individuals who all played a part in different departments that typically had little communication with one another. Its headquarters alone employed 10,000 staff members by 1920 , excluding head office personnel. ${ }^{11}$ This chapter highlights the division between the research and engineering departments, and between the telecommunications and sales departments, revealing that these two branches had largely divergent views on the necessity of providing amplified telephony. This may have been because the Engineering Department was further removed from the problems that customers were bringing to their local district managers or sales departments. Any problems related to engineering work had to be routed from the local divisions to headquarters in London, which meant any new installations of telephone equipment were mired in interminable complications. ${ }^{12}$ Any meaningful decisions regarding amplified telephony were made in the London headquarters, with input from the Research Department. Furthermore, until the 1932 Bridgeman Report prompted reform, the telephone network was severely restrained by the financial constraints imposed by the higher echelons of this massive administrative network, the Postmaster General and the Treasury. Essentially, the Post Office telecommunication services were still being run on the structure of the old National Telephone Company, which the Post Office officially took over in 1911.

This followed on from the 1880 decision that the Post Office (as the government's branch of communications in control of the telegraph system) would take over the trappings and apparatus of the National Telephone Company. The National Telephone Company (NTC) was the Bell and Edison conglomerate which had controlled most of telephony in Britain before the 1880 ruling on the 1869 Telegraph Act mandated a nationalised service - officially instated 
in $1911 .^{13}$ As a result, in the intervening thirty-one years, the National Telephone Company had no reason to invest in its stock, and so let its equipment and researches stagnate. Thus, the company that the Post Office inherited was lagging far behind the telephone companies spreading out across Europe. ${ }^{14}$ The Post Office Telecommunications Department barely had three years to consolidate before the First World War broke out, which had a devastating impact on the Post Office's ability to invest in the telephone system.

The First World War generated a new need for telephones for those with hearing loss. The conflict had accustomed a generation of soldiers to the use of telephony, which they then desired to use at home. But their wartime service had also left many of these same soldiers with myriad hearing loss problems, which raised the profile of deafness as a national concern. This development not only made the treatment of deafness a greater priority for the medical profession, but also changed attitudes towards deafness as perceptions of treatment shifted. This shift influenced a move away from treatments derived from eugenics-based ideologies which conceptualised deafness as a purely hereditary condition, to rehabilitation movements based around the theory that noise-induced deafness could affect anyone. War-induced deafness also meant that there was an acknowledgement of social responsibility (manifesting in various charitable movements for disabled veterans) as well as an official policy of state intervention reflected in the establishment of the Ministry of Pensions in 1916.

The Post Office's duty to provide an amplified telephone must be considered in the context of these interwar welfare developments. The Post Office had total control over the telephone network. However, this state backing meant that the Post Office was required to work under the financial constraints of the Treasury and act as an arm of the wider government. The Post Office was a state office of the government, which had increased involvement in the welfare of its citizens from the start of the century, marked through legislation like the National Health Insurance Act (1911) and the creation of the Ministry of Pensions (1916) and the Ministry of Health (1919). The First World War further increased the newly enfranchised public's expectations that the government was responsible for citizen welfare. Disabled veterans returning from the First World War created a need for increased government intervention into public welfare and thus, as an arm of government, the Post Office had to have increased consideration of veterans who had become disabled as a result of their role in the First World War. Amplified telephony was developed according to, and alongside, the emerging priorities of this proto-welfare state. The Post Office's legalised control over the telephone service in Britain meant it was illegal for private companies or individuals to modify or tamper with its 
apparatus. Crucially, this meant that private hearing aid companies could not attach equipment to Post Office telephones and people with hearing loss could not fit private telephones for use on Post Office lines. Consequently, the Post Office was challenged by aspirational users who desired a telephone that could be used by people with less than perfect hearing.

The Post Office was aware of how hard it was to hear the telephone. In 1923 they proffered advice on how to speak with maximum audibility and effectiveness, counselling subscribers to speak 'clearly' and 'distinctly' and warning that the telephone would blur consonants and elide vowel sounds (see Figure 3.1). As we can see from their advice sheet, accents which blurred vowel sounds were detrimental to clear communication. The telephone consequently worked before and then alongside radio to standardise received pronunciation as ideal for media communication during the early twentieth century. ${ }^{15}$ This argument offers parallels with the analysis provided by sound historian Victoria Thaczyk concerning the forced development of a standardised 'normal' media language in Germany in the interwar period, which was, as she shows, facilitated by the gramophone and designed 'to convey an impression of scientific objectivity.' ${ }^{16}$ More pertinently for my argument, the Post Office's guidance makes it clear that the process of telephone transmission made speech less comprehensible for those with hearing loss, especially those with noise- or age-induced loss, for whom higher frequencies (the pitch at which the information delivering consonants is delivered) were lost. ${ }^{17}$ The Post Office clearly understood the difficulties of using the telephone. Why did they not invest more immediate research into improving sound quality, then? To answer this, we need to understand the historical context influencing the Post Office's structure, and its relationship with the government as a nationalised company.

\section{The deafened}

The technology used in amplified telephone equipment developed very much in tandem with the technology used in trench telephony in the First World War. Telephony increased in use and improved in amplification thanks to the valve technology that was used in the trenches and designed by the Post Office. It was this very technology that came to be redeployed in a civilian context to facilitate increased communication for those with hearing loss after the First World War.

Hearing loss was highlighted as a national problem because of the increased attention given and importance attached to hearing during the conflict. For the first time in the First World War the telephone was used as a crucial mode of communication for the British Army, and the Post Office was essential to 


\title{
POST OFFICE TELEPHONES.
}

\author{
HOW TO PASS AND RECEIVE A TELEPHONE CALL.
}

\section{PASSING A CALL.}

Before passing a call to the Exchange the subscriber should wait until he hears the telephonist's "Number, please?" and then, speaking CLEARLY and DISTINCTLY, with the lips almost touching the mouthpiece, he should state the number required.

FIRST the name of the Exchange and THEN the number.

The method of pronouncing numbers in Telephone Exchanges has been devised to guard as far as possible against inaccuracies and a description of the system may be of assistance to subscribers.

It is important to remember that the distinctive sounds of consonants become blurred in the transmission of speech by telephone and words containing the same vowels are apt to sound alike. Greater care is therefore necessary in speaking by telephone than is required in ordinary speech, if mistakes are to be avoided.

$\mathbf{O}$ is pronounced as "OH," with long "O."

1 " "WUN," emphasizing the consonant "N."

2 " " "TOO," emphasizing the consonant " $\mathrm{T}$ " and with long "OO."

3 " " "THR-R-EE," with slightly rolling " $\mathrm{R}$ " and long " $\mathrm{E} . "$

4 " " "FOER," one syllable with long "O."

5 " " "FIFE," emphasizing the consonants "F."

6 " " $6 \mid \mathbf{X}$," with long "X."

7 " " "SEV-EN," two syllables.

8 " "ATE," with long "A " and emphasizing the consonant "T."

$9 \quad " \quad$ " "NINE," one syllable, with long "I" and emphasizing the consonants "N."

ANSWERING A CALL.

The call should be answered promptly.

On taking off the receiver, the called subscriber should not say "Hullo!" or "Who's there?" but should immediately announce his name.

A householder would say : "Mr. Thomas Brown speaking."

The maidservant : "Mr. Brown's house."

Mr. Brown, at his office, would say : "Brown \& Co., Mr. Thomas Brown speaking." His clerk : "Brown \& Co."

\section{FINISH OF CONVERSATION.}

The receiver should be replaced immediately the conversation is finished. Subscribers having Private Branch Exchange switchboards should ensure that adequate arrangements are made for PROMPT DISCONNECTION AT THE SWITCHBOARD. Neglect to do this may result in serious inconvenience.

General. Post Offick.

October, 1923.

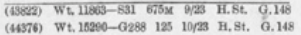

Figure 3.1 'How to pass and receive a telephone call', in 'Guidance for Subscribers on How to Articulate and Pronounce Vowels and Consonants, and Phrases to Use When Speaking on the Telephone', October 1923

the development of wartime communications. Most significantly, it supplied telephones specifically designed for the conditions of the trenches. ${ }^{18}$ Although the telephone had been taken up by the military soon after its invention, and used in the Second Afghan War in 1879, it was not a popular form of military 
communication. ${ }^{19}$ When the First World War began, the military dismissed the telephone as unimportant and unsafe compared with telegraphy, visual signalling or motorbike couriers. ${ }^{20}$ However, the trench warfare conditions that developed as fighting came to a stalemate prompted a rethink over the practicality and utility of telephony. In the dark, underground, isolated trenches, the telephone became a lifeline and an essential tool for communicating and working out what was happening 'over the top'. One corps commander emphasised that the telephone equipment was extremely valuable and ordered that 'the equipment should, therefore, be treated as if it were made of glass, and as if it were as valuable as diamonds.' ${ }^{21}$

Wartime needs put pressure on the Post Office's equipment and researches, but also worked as a catalyst to spur the development of specialised auditory equipment, resulting in concurrent improvements to amplification, audibility and portability. The sudden military demand for telephone equipment could not be met by the small supply originally stored, and the Post Office became the Army's main supplier. In 1920, the total value of the communications equipment the Post Office had supplied was $£ 6,400,000$ and included 40,000 protected telephones, designed specially for the trenches. ${ }^{22}$ Telephony's usage in warfare thus involved a huge investment from the Post Office, and it was able to use the specific conditions of trench warfare to experiment and test the limits of the equipment. ${ }^{23}$ The Post Office's signal services and research departments were integral to the development of specialist telephone equipment for use in a military context. For example, the Post Office designed the hot wire microphones that allowed the British Army to obtain precision sound ranging. Recalling the Post Office's contribution to the war in 1920, Post Office Chief Engineer Sir Andrew Ogilvie explained:

The assistance of the Post Office was sought by the inventor, and I am proud to say that Mr Pollock, the head of the engineering Research Station, and his assistants not only devised a successful microphone on Capt. Tucker's plan, but also manufactured many thousands in a secret factory in the General Post Office, thus making a practical success of this very important invention. ${ }^{24}$

The Post Office also devised hypersensitive transmitters that were placed on the parapets of opposing trenches and used to spy on enemy conversations and monitor the conversations of prisoners of war. ${ }^{25}$ The Post Office's development of these transmitters was directly influenced by hearing aid technology, just as the development of hearing aid technology was influenced by wartime technology. ${ }^{26}$

By 1918 the Post Office had spent an estimated $£ 7,000,000$ on the war effort by designing and manufacturing communications equipment for the 
military as 'Wire, cable, telephones, switchboards and signalling apparatus of new and varied types poured across the channel in ever-increasing quantities. ${ }^{27}$ Yet this innovative technology was not necessarily appropriate for peacetime. In 1919, William Cruikshank, the editor of the Post Office's Electrical Engineer's Journal, bemoaned the fact that 'the great proportion of this plant is of special design to meet military requirements, and would be of little use for civilian service if recoverable tomorrow' ${ }^{28}$ The huge amount of equipment supplied to the Army meant that there were domestic shortages as manufacture for home use decreased dramatically. British industrial factories were taken over to produce shells and telephone equipment specifically for the Army. This led to complaints at the end of the war, which the editor of the Electrical Engineers' Journal did not receive in good grace, angrily responding: 'He who asks, "Where are the wires to join up my telephone to-morrow, and why are they not available?" will receive the same answer he would have received had he asked, "Where are the men of the old Contemptible Army?" "They lie buried in the soil of France and Flanders". ${ }^{29}$ However, by recycling the technology of the trench telephones into technology for those with hearing loss, the Post Office was able to appropriate the military equipment for civilian use as dedicated equipment for those with hearing loss. ${ }^{30}$

Trench warfare necessitated research focused on improving amplification range and quality while simultaneously creating more portable sets that could be easily carried in soldiers' packs and set up in trenches; civilian telephones did not function well in the damp and mud of a trench. ${ }^{31}$ Just as in the case of electric hearing aids, there was constant tension between the ability to improve audibility and retain portability, as an improvement to the latter tended to diminish the former. Amplification of telephony had long been a crucial issue for the Post Office. Its Engineering Department had been working with cathode rays to provide amplification as early as $1908 .^{32}$ The Electrical Engineers' Journal explained that these experiments were subsequently abandoned due to staff shortages, but were revived in 1913 after the thermionic valve was developed in the USA. ${ }^{33}$ John Ambrose Fleming (who also had hearing loss) invented the thermionic valve while working for the Marconi Company in 1904. In 1906 Lee de Forest added a third electrode, meaning that those valves could be used for amplifying electrical currents. This greatly improved long-distance telephony, but it was not until 1915 that they were used in European telephones. ${ }^{34}$ A challenge for innovation in the military context arose from the fact that the patent for the thermionic valve was held by Marconi and lasted until 1918. ${ }^{35}$ The first valves used in Post Office telephones were 'round' French valves which were incorporated into its earliest telephone 
instruments. These valves boosted the electrical signal, and thus increased amplification.

The potential power of the thermionic valve as an amplifier was emphasised in the Electrical Engineers' Journal in 1919, in which the editor explained how war activities had accelerated development.

In no branch of the nation's activities - save perhaps in the development of aircraft - has there been such useful progress made during the war as in wireless telegraphy and telephony. The evolution of ... the oscillating thermionic valve, has been one of abnormal progress, and has placed in the hands of the engineer an instrument pregnant with possibilities. ${ }^{36}$

The possibilities of amplification offered by valve technology were realised not only in general improvements to telephone audibility but also ultimately in hearing aid technology and in the telephones designed for users with hearing loss. Moreover, the work that the Post Office did for the government during the First World War signalled the start of an increasingly collaborative relationship between the state and the Post Office. This 'special relationship', as it was often referred to by the Post Office during the interwar years, was integral to motivating the Post Office's development of its amplified telephone service for the deaf. Thus, the technology used in amplified telephone equipment developed very much in tandem with the technology used in trench telephony in the First World War. The same technology was redeployed in a civilian context to facilitate increased communication for the hard of hearing after the First World War.

General attitudes towards the deaf prior to the First World War were formed through segregating the deaf as a separate, problem social group. Care of adults with hearing loss was left entirely to publicly funded charities, so adults suffering from hearing loss in the late nineteenth century were offered little assistance. Treatments for deafness were preventative and often informed by eugenic principles. ${ }^{37}$ The state had little involvement in the care of those with hearing loss, although deaf children were cared for in schools established throughout Britain during the nineteenth century. But adults who became deaf later in life had to rely on charitable provision. ${ }^{38}$ To meet this need, the National Bureau for the Promotion of the General Welfare of the Deaf (henceforth the Bureau) was established in 1911 by deaf merchant banker Leo Bonn. It was intended to be an umbrella organisation, which would centralise the different charities working independently to help the deafened. It was established partly to ensure that the deaf were not classified as mentally defective under the Mental Health Act of 1913, and partly in reaction to the drop-off in employment of deaf workers that had followed the National Insurance Act of 
1911. ${ }^{39}$ The Bureau was renamed the National Institute for the Deaf in 1924 and was granted the prefix 'Royal' in $1961 .{ }^{40}$ Its work was supplemented during wartime by the National Benevolent Society, which was expressly established in 1918 to meet the needs of deafened ex-service men. The society reported in 1918 that:

The general public is only just beginning to realise as yet that the Deaf are as greatly in need of help as the Blind, and need all our best effort in many directions and our thoughtful care. The 'After Care' work for 10,000 deafened soldiers, sailors and airmen has required incessant and untiring effort and has been widely welcomed by War Pensions, Secretaries, and greatly valued by the men. ${ }^{41}$

The government officially endorsed this society in 1919 by licensing it under the War Charities Act to collect funds from the public on behalf of ex-service men. ${ }^{42}$ The National Benevolent Society concentrated initially on administrating the Deafened Ex-Service Men's Fund and providing ex-servicemen with employment advice, loans, re-training and help in claiming pensions and pension arrears, sometimes through specialist re-examination. They were aware that deafness scaled very low in the assessment for pensions, and that large numbers of seriously deafened men received little more than $11 \mathrm{~s} 9 \mathrm{~d}$, or $15 \mathrm{~s}$ $3 \mathrm{~d}$, to provide for themselves and their children. Furthermore, like the women working during the war, many deafened men had lost their jobs when men with better hearing returned from the front. Their hearing loss was exacerbated with age and by 1929 the National Benevolent Society reported that there were now 'a good number of cases unfortunately losing their employment owing to increasing deafness, which disability debars a man altogether from employment on the railways, in the mines, and at the docks. ${ }^{43}$ This kind of disability was increasingly viewed as a new category of deafening. In 1934 the Bureau reported on the division between the 'deaf-born' and the 'deafened' under the sub-heading 'The Problem before the Institute':

The deaf fall actually into two general classes, according to the history of their affliction and from the psychic point of view these classes are essentially distinct ... The problem before your committee is therefore of a two-fold nature, necessitating separate lines of action to meet the distinctive conditions of the deaf and dumb and the deafened. ${ }^{44}$

This was a key shift in terminology that reflected the growing understanding of hearing loss gained from the war: that deafness could originate from external factors rather than purely hereditary causes or disease. Although there is not scope in this book to fully explore the way that the First World War impacted on changing categorisations of deafness, Graeme Gooday and Karen Sayer's 
book offers a nuanced and detailed account of these changes, and shows that the spread of telephony and radio after the war to help the war-blinded further alienated the war-deafened. ${ }^{45}$

Increased awareness and understanding of hearing loss was not the only change marked by the First World War, which also demonstrated how important the sense of hearing could be. One of the features that distinguished the First World War from the many conflicts that preceded it was that so much of it could not be seen by the men involved. ${ }^{46}$ In dark, troglodytic trenches, hearing was prioritised over sight, and listening became a tactical survival skill with listening posts and sound-ranging techniques (as well as new electro-acoustic technologies) developed to help identify and target the opposition. ${ }^{47}$ Therefore, in the First World War trenches, hearing came to occupy a place alongside sight as a crucial sense. The increased importance of sound and hearing in trench warfare was augmented by the impairment to vision. Yet the intense listening required by soldiers was not solely a product of sight deprivation but was also used to map out the surroundings. For example, soldiers could listen to establish the weak spots of enemy defence fortifications and the areas of most intense gunfire. ${ }^{48}$

Ironically, despite the increased importance attached to the aural, it soon became apparent that the tremendous sonic bombardment delivered by shelling and artillery fire was causing widespread hearing loss. Many soldiers who appeared to be suffering from shell shock also presented with symptoms of deafness and deaf mutism. After the conflict it became apparent that this hearing loss was temporary or symptomatic in some cases, permanent or noiseinduced in others and only rarely hysterical. But initially all conditions were conflated, and various treatments were devised for their cure. This conceptual shift which saw hearing loss as psychological or functional was marked by the intervention of psychiatry into a domain traditionally dominated by otology. ${ }^{49}$ Conceptual concerns about hysterical deafness and the potential for malingerers to feign deafness became embedded in the field of audiometry, which we will discuss further in Chapter 4. But before doing so, we need to understand where the data on normal hearing used in audiometry came from, and for that we need to return to the Post Office telephone service and its instrument for measuring normal hearing - the artificial ear.

\section{The artificial ear}

The data used by Post Office engineers in the artificial ear created the standards that were used to design 'normal telephones' in Britain. If users did not have the ability to use the normal telephones, then it followed that they had to 
use the 'telephone service for the deaf'. Therefore, the data used in the artificial ear and fed into telephone design mediated what we would now think of as a medical condition. Yet deafness was not always conceptualised as such.

In 1908 the National Telephone Company (the NTC) created a 'mechanical ear', which was designed to work in conjunction with an artificial voice. The artificial voice was designed by the NTC by recording and measuring the frequencies of five women who counted the numbers one to five repeatedly the standard way of making transmission tests. The woman with the most pleasing voice was determined through a vote which the men in the office took part in, and a professional soprano singer was also enlisted to record what was considered to be an ideal frequency. Conversely, similar attempts made at Bell Laboratories in the 1940 s to make a visual record of the voice used 'a store of examples from hundreds of speakers. ${ }^{50}$ However, in the second half of the twentieth century, the engineers at Bell Laboratories decided that the patterns of speech form were more important than frequency for recognising speech and so only used measurements from men and children, the values of which were 'averaged across all the repetitions to serve as the final "typical" value. ${ }^{51}$ Using this kind of statistical approach is why voice recognition machines like Siri and Alexa still have 'significant race and gender biases. ${ }^{52}$ However, it is important to note that Bell Laboratories were pioneering this approach to facilitate speech recognition through a spectrograph, whereas the NTC's mechanical voice was designed as a simple testing device to work in conjunction with the artificial ear. Their final arrangement was measured by an artificial ear that we would think of as more closely resembling a recording device than a replica of a human ear. This allowed for quick and mechanical assessment of the telephone's transmission quality. Its advantage lay in the fact that the telephone circuit was not interfered with, and it gave comparable results to a 'human test' but was 218 minutes faster. The NTC report concluded that: 'There is thus a saving of $67 \%$ in time, in addition to the fact that mechanical testing is of course not nearly so exhausting as speech testing. ${ }^{53}$

The next available report on this subject was produced in 1928, indicating that the Post Office continued using the NTC system during the intervening twenty years. ${ }^{54}$ The 1928 report marked a critical change in practice, and in the way that the artificial ear was designed and used. Rather than functioning solely as a testing system, the artificial ear was redesigned by the Post Office to resemble a real ear as closely as possible, replicating the functions of the outer, middle and inner ear, shown in Figure 3.2 from left to right.

The Post Office explained that: 'the present investigation aims at a quantitative determination of the acoustical impedances of a reasonable number of normal (male) ears over a considerable frequency range.55 This reasonable 


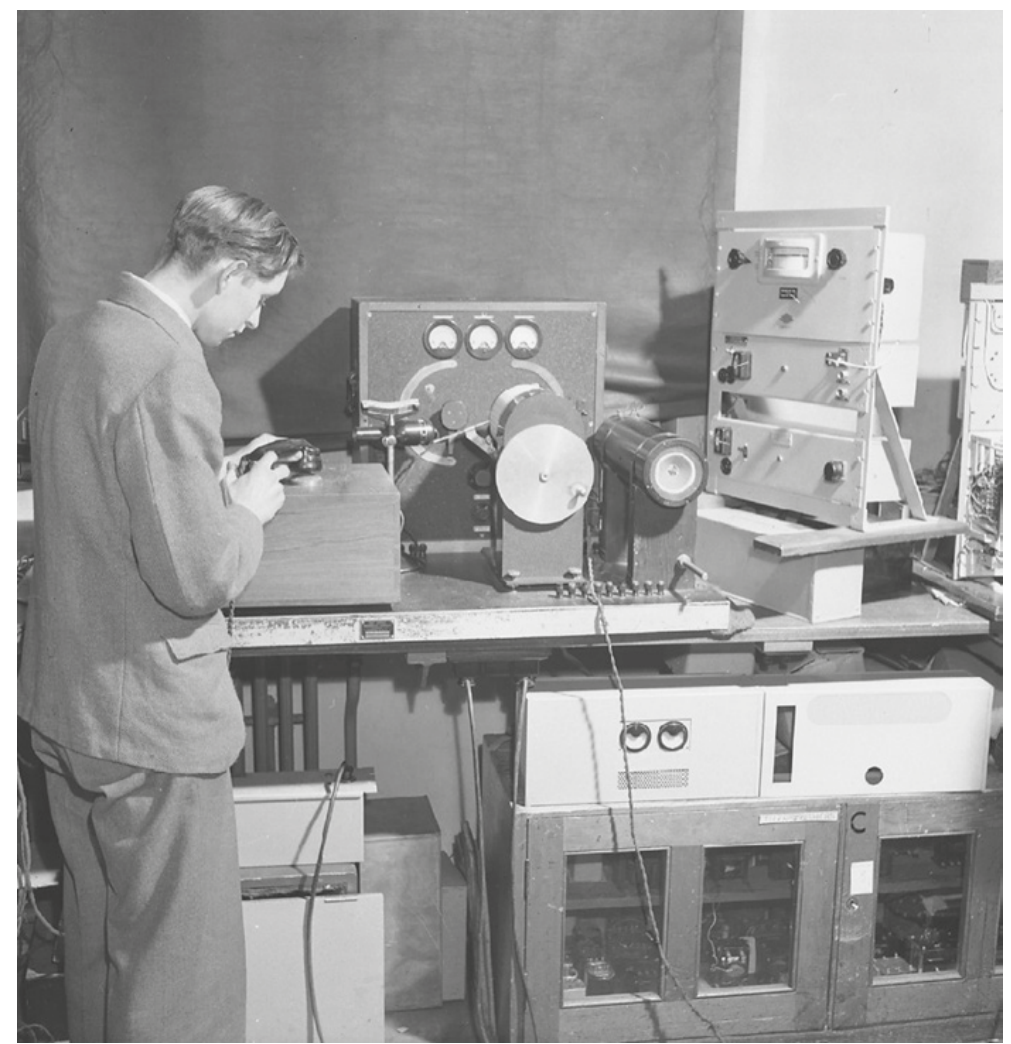

Figure 3.2 The artificial ear, Post Office Research Station, Dollis Hill

number consisted of twelve ears altogether, ten 'normal' male ears and two 'abnormal' ears. The data gathered through tests on the normal ears were used to provide the representative standard of normal hearing. These 'normal' ears were tested for the mean and extreme resistances to different frequencies, with the average value used to design the artificial ear. However, it is clear that there was relevant information garnered from the ears that did not function as expected, as the two abnormal ears were given further tests to establish their 'impedance' values, which meant that the Post Office engineers investigated the extent to which the abnormal ears were able to transmit sound through vibrations:

During the investigation two ears, which were abnormal in that their hearing was known to be below normal, came under observation. In both cases 
the impedances were found to be abnormal, one giving an exceptionally high value and the other an exceptionally low value of absorption at 1100 cycles per second. ${ }^{56}$

Understanding impedance (the conversion of vibrations) was important in improving the artificial ear's design, as the electrical impedance of the artificial ear had previously been adjusted with a real ear.

An artificial ear was considered by the Post Office to be superior to real ears for testing telephone transmission quality for four main reasons. First, it gave quantitative data 'for measurement, in absolute units, of the performance of receivers under their working conditions. ${ }^{57}$ Second, it increased the possibilities of testing volume measurements and comparing different circuits and techniques on that basis. ${ }^{58}$ Third, and most importantly, the artificial ear provided a permanent trace, a record that did not depend on consistent reproduction and a large number of tests. Many tests were necessary in any use of real ears for research because of the variability of hearing abilities: 'wide discrepancies between results with different observers necessitates a larger number of tests and observers in order to obtain a representative average. ${ }^{59}$ Such a testing process was felt to be particularly problematic because of its subjective nature, therefore 'the elimination of personal bias by the use of an artificial ear becomes more important. ${ }^{\prime 0}$ Thus, fourth, the artificial ear was conceptualised as an objective technology that could be used to manage the variability of hearing. The resulting machine designated standards of normal hearing in narrow mechanical parameters, which led to a situation in which those who did not fit with the Post Office telephonic standards were categorised as deaf, and in need of a 'telephone service for the deaf'. Such telephones were developed during the interwar years through a series of user-forced innovations, as we will see in the following section. Telephone users (such as those with greater hearing loss, different frequency needs or bone-conductive hearing losses) were unhappy with their telephone provision and demanded that the institution fulfil its duty to provide telephone access to all types of citizens. Moreover, the National Institute for the Deaf (the ancestor of the Bureau and henceforth the NID) attempted to improve the provision of electric hearing aids sold during the interwar period by testing them using this machine. ${ }^{61}$ It was also used in the design of the first NHS hearing aid, the Medresco. ${ }^{62}$ This hearing aid was intended for children and yet data related to children's hearing was not used in the artificial ear.

While it seems strange that this distorted normalcy standard could have remained embedded in the artificial ear between 1928 and 1947, I can find no further investigative reports after the 1928 report, only references to the 
artificial ear as the standard device against which hearing aids and telephones were calibrated. The Post Office was not a medical institution, and there was no need for it to search for increasingly accurate data. What was wanted was an efficient and successful standard, and, after all, a successful standard is marked out by its invisibility. For instance, Rachel Weber pointed out in 1997 that the only anthropometric data for civilian female populations was from 1940 but was still being used in commercial plane cockpit design. ${ }^{63}$ Similarly, Lundy Braun has shown that the spirometric data used for race-specific population standards endured far longer than one would imagine to be appropriate - data gathered by Samuel Cartwright, a Southern physician and slave owner, was used in a germinal study by Benjamin Apthorp Gould that is still cited today by pulmonary researchers. ${ }^{64}$ She points out that designing new data sets 'sufficiently large to be scientifically credible' is a drain on time and finances. ${ }^{65}$ For the Post Office, the standard of normal hearing was not meant to be medically credible but was simply a useful economic tool: why would they spend time and money on more representative data?

\section{Case studies: individual users versus institutional innovations}

Telephony was ultimately used as a tool in the categorisation of disability by the Post Office. The amplified telephone was used by the Post Office to categorise their users' identity as either hearing (could use the standard telephone model), hard of hearing (could use the telephone when amplified) or deaf (could not use the telephone even when amplified). Categorisation largely depended on the efficacy of the technology rather than on the telephone user's level of hearing. The first of these aspirational telephone users were the Smith brothers. The brothers ran an eponymous oil distilling and refining company from 24 Marshgate Lane, Stratford, London, and they opened a dialogue with the Post Office early in 1922. One of the brothers in charge of the company, $\mathrm{Mr}$ Worringham Smith, had substantial hearing loss. They wrote to the Post Office in 1922 and advised that their company had lost business because their director was unable to use the telephone, and they pleaded that they were 'willing to pay any sum within reason for facilities which will enable them to interpret their telephone messages'. They added that 'At present they are of the opinion that many orders are lost owing to their defective hearing. ${ }^{66}$ Businessmen were one of the first key groups to embrace telephony in the latter years of the nineteenth century and the Smith brothers demonstrated the negative impact that telephone exclusion had on their business. ${ }^{67}$ Their request was initially made in a detailed letter dated 12 January 1922, in which the author (probably Mr Worringham Smith) made two main points to persuade the Post Office 
to provide this service. First, he pointed out the lack of progress that the Post Office had made since nationalisation in 1912 and compared its service to private companies like the NTC: 'If we were not hidebound by your Authorities regulations - which forbid us - we think we are right in saying a private maker would very soon give us what we want the same as the great National Telephone Company would have done - with an extra sensitive instrument (we do not mind paying). ${ }^{6}$

This letter pointed out that this was an equity issue, and further argued that the requisite amplification technology was already available and used in telegraphy: 'In wireless telegraphy, as you know, they use amplifiers which greatly magnify the sound. Could not something of the sort be adapted to telephony, so that people with hearing below the normal could be placed on the same footing as those with normal hearing?' ${ }^{\prime 9}$ The amplified telegraphy referenced in this instance was the repeater system, which used thermionic valves along the line to prevent sound from weakening over distance. ${ }^{70}$ The reason that this was in use for telegraphy long before being adapted to telephony is that the repeaters could amplify the static signal used in telegraphy but were unable to work in the same way with the undulating signals produced by the voice in conversation. $^{71}$

The original suggestion by the Smith brothers in their 1922 letters regarding amplified telephones for the hard of hearing was entirely feasible, and the Post Office did adapt 'something of the sort' (as the London superintending engineer Mr Purves put it) in response. Purves initially reacted by sending a letter to the engineer-in-chief which asked 'if there are any loud speaking receivers or other suitable devices to meet such cases? ${ }^{72}$ The engineer-in-chief responded to his request by developing specialist amplification apparatus and inviting the subscriber (Mr Worringham Smith) to try it out. Mr Smith wrote that he was 'very favourably impressed' by the instrument and agreed to an annual rental addition of $£ 515$ s to have it fitted to his telephone. ${ }^{73}$

On 10 April 1922 the London superintending engineer wrote to the engineer-in-chief to ask, 'Is it to be understood that this type of apparatus will be available for other subscribers? If so, presumably the Engineer-inChief will desire to consider all applications for its provision? ${ }^{74}$ However, the engineer-in-chief replied that: 'it is not desirable that the provision of amplifiers should be suggested to subscribers, but in special cases where a request for such provision is made and it is clear that the subscriber would benefit thereby it will in all probability be possible to supply the required facilities' ${ }^{75}$ This refusal could only plausibly be attributed to the prohibitive costs and exemplifies the way in which the Sales and Telecommunications Department of the Post Office was often at odds with the Engineering Department; the 
former tended to show more enthusiasm for an amplified service than the latter. The difficulties involved in improving the amplification technology were no doubt a deterrent from an engineering perspective, compounded by the added expense incurred by adding the extra apparatus. Even though this extra cost to the Post Office could be offset by increasing rental, the cost of repairing the delicate valves meant that developing amplified telephony made little fiscal sense.

Reluctance to develop specialist services can also be attributed to the conservative nature of the Post Office institution and the way that the government influenced its attitude towards development. US historian Charles R. Perry has emphasised the extent to which ideology influenced telephony in Great Britain in comparison to the way private telephony companies developed in the USA. ${ }^{76}$ The Post Office's reluctance to anticipate demand is the aspect that Perry highlights, and he attributes this to the Treasury, whose ideology was summed up by a clerk who wrote that:

The sound principle in the opinions of My Lords is that the state, as regards all functions which are not, by their nature, exclusively its own, should, at most, be ready to supplement, not endeavour to supersede, private enterprise, and that a rough but not accurate test is, not to act in anticipation of possible demand. ${ }^{77}$

The Post Office was discouraged from innovation by the government because acquiring new information about as yet non-existent services was expensive. ${ }^{78}$ The Post Office's reluctance to innovate and advertise its services in a relatively specialised area such as amplified telephony can therefore also be attributed to the expense of research as well as being in line with broader government policy. The possibility of developing and advertising amplified telephony was consequently only considered after repeated complaints by irate customers who desired access to the service.

The first telephone designed specifically for people with limited hearing was not advertised until 1924, when a brief description of the 'Repeater Telephonic 9A' appeared in a press release that described a telephone 'for the use of "Deaf Subscribers" who experience difficulty in the use of the standard telephone. ${ }^{79}$ This early amplified telephone (the Repeater 9A) featured a controlling key to modify the volume as necessary, which was stored in a separate wooden box, along with the valve amplifier. ${ }^{80}$ This aspect of its design was later modified, following customer criticism. The desk-based design reflected the imagined needs of the intended business user, but the box was very unpopular with customers, who found it both cumbersome and stigmatising. The extra rental involved in its hire was also unpopular with customers, some of whom went to great lengths to reduce its price. 
We now meet Mr Buckley, a schoolmaster who had lost some hearing in the First World War and worked at Magdalene Court Boarding School in Broadstairs, Kent. He described himself as slightly deaf due to his long war service and in need of telephone access to contact the parents of his boarders (who were usually in London). In the late 1920s, there were still problems with increasing attentuation over long distances which could exacerbate the difficulties of hearing on the telephone, especially for those living in the countryside. Mr Buckley's complaint was not with the efficiency of his amplifier, however, but with the cost of rental. He made a number of points to support his claim that it was overpriced, attacking the Post Office in two main ways: first by highlighting the fact that the institution had a duty to their customers, especially if they had lost their hearing through war service, and second by threatening legal action to remove the Post Office telephone poles on his land.

He started his complaint by writing directly to the Postmaster General on 19 October 1928 with the explanation that he was 'slightly deaf' and struggled to hear country calls clearly. ${ }^{81}$ Following on from this he stated that he had enquired into the cost for an amplifier and explained that 'the local engineers who do our wireless tell me that they are not allowed to fix an amplifer; that the actual cost is only a few shillings and that the proposed charge by the local Telephone Manager is exorbitant'. ${ }^{\prime 2}$ The Postmaster General responded in December, pointing out that 'valve amplifers are relatively costly to maintain', which accounted for the increased rental cost. ${ }^{83}$ The Post Office did, however, agree to reduce the original sum demanded and also explained that the Engineering Department were trying to design a cheaper version. This was not enough to placate Mr Buckley, however, and he quickly replied, emphasising the fact that 'the price charged by the Post Office is out of all reason'. ${ }^{84}$ His grievance was not just based on the fact that he thought that the Post Office was overcharging for electrical equipment, however, and he explained:

I considered that it was the duty of the Department to make these charges as little as possible for the convenience of the telephone subscribers, that the necessity for the amplifier arises out of my deafness which is a result of my long war service and for which I am in receipt of a small pension for life. ${ }^{85}$

By referencing his war service and the fact that he received a small pension he pointedly reminded the Postmaster General that the government was taking greater responsibility for the welfare of its citizens. This case came to a close only when the Post Office designed a cheaper version of its amplifier which Mr Buckley agreed to rent at reduced cost with a freehand microtelephone. His resort to legal action and his threats to take the Post Office to court were clear demonstrations of how important the telephone was to him 
and also indicated his strong belief that on principle, the Post Office should support the men who had lost hearing in the war. Mr Buckley's status as a war veteran gave him more leverage to argue his case thanks to the government's alleged post-war commitment to disabled veterans. The improved amplified telephone (the Repeater 17A) was released in $1934 .{ }^{86}$ This was a cheaper amplifier with a freehand microtelephone (see Figure 3.3). As well as being freehand (meaning the volume control was embedded in the telephone itself rather than in a box) this model used a more powerful valve to boost the signal and increase the volume.

The advertisement shown in Figure 3.3 was released in a campaign in 1936 to market the amplified telephone as 'A Telephone for Deaf Subscribers'. The term 'Deaf Subscriber' was itself contrived to group people with limited hearing together, without considering the wide spectrum of hearing abilities.

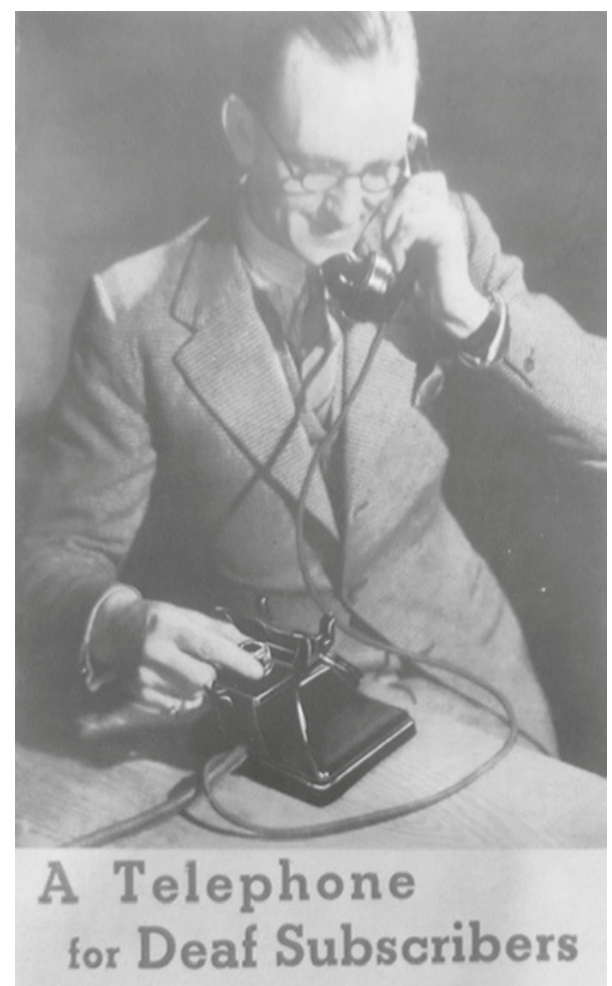

Figure 3.3 Advertising booklet, 'A Telephone for Deaf Subscribers', 1936 
During the interwar period, it was understood that hearing limitations varied in intensity, but understanding of the difference between sensorineural and conductive deafness was in its infancy. The need for modification of volume at specific frequency levels was recognised by the Post Office in 1936, when a report on 'Aids to Telephone Reception for Partially Deaf Subscribers' investigated the possibility of designing an aid which would amplify sound alongside an alternative frequency characteristic. ${ }^{87}$

The Post Office's understanding of the variability and individuality of hearing limitations was influenced at this point by its collaboration with the medical scientist Dr Phyllis Kerridge. Her 1935 report on 'Aids for the Deaf' in the British Medical Journal was extensively cited in their report. ${ }^{88}$ The 'problem of deafness' was thus moving from a problem to be solved by engineers into the realm of medicine. However, the principal group targeted by the Post Office in attempts to popularise amplified telephones would not have automatically identified as deaf and may have passed as hearing in all other aspects of their lives. ${ }^{89}$

Those who desired access to telephony in the interwar years would almost certainly not have recognised the Deaf community and its cultures of the late twentieth century, but less scholarly attention has been paid to those who lost hearing later in life and did not affiliate themselves with the Deaf community. This is in part because there was not an identified community of people with hearing loss, and in part because the stigma surrounding deafness led those with limited hearing to identify as hearing and minimise the significance of their hearing loss.

In modern Deaf culture, hearing loss or limitation is not regarded as disabling. Rather, the Deaf regard themselves as being defined not by their medical status but through their social and political status. ${ }^{90}$ The point in emphasising this terminology is to demonstrate the spectrum of deaf experience and note that those who would describe themselves as deaf during this period would likely not have used the telephone, and those who struggled with it would have described themselves as hearing or possibly as hard of hearing. Crucially, the amplified telephone enabled those using it to 'pass' as hearing over the telephone during a period when the stigmatisation of hearing loss was high. ${ }^{91}$ The amplified telephone promised to solve issues of both audibility and stigmatisation without being apparent to the caller on the other end of the line. Although the amplifying apparatus used in the design of the modified telephone was bulky and visible to its user, it was invisible to the caller on the other end. The invisibility of the amplified telephone as a prosthetic is particularly salient to hearing loss, itself an invisible disability which is often only revealed by the relevant assistive technology. ${ }^{92}$ 
However, the integrated receiver of the Repeater 17A, which was a significant change from the older candlestick-style receiver and transmitter, attracted the ire of users with hearing loss who had been using the older models to listen to the telephone using bone conduction - pressing the receivers to their mastoid bone and comfortably listening to the receiver through vibration while speaking into the separate mouthpiece. The Post Office explained that such users 'had been accustomed to holding the bell receiver to the bone at the back of the ear to obtain best reception for his [sic] particular deafness. ${ }^{93}$

As a result of this problem, Wiltshire-based engineer Mr Raymond Harris designed and built his own personal amplifying apparatus which he used in conjunction with the Post Office telephone and insisted was far superior to even the most recently advertised equipment. As I have discussed in more detail elsewhere, the development of the amplified telephone service involved direct appropriation of the embodied knowledge of telephone subscribers with hearing loss, as we can see in the protracted struggle between Harris and the Post Office. ${ }^{94}$ Whilst Harris believed that the Post Office should have been able to provide apparatus at least as good as his own for anyone suffering from hearing loss, the Post Office did not want private apparatus used on its lines, but simultaneously did not want to waste money designing specialised apparatus for a single customer.

After Harris made it clear that he was not satisfied with the new telephone (the Repeater 17A), the Post Office responded by visiting his home to check that its equipment was working. At this point it realised that the newly advertised instrument was not supported in his service area and Harris was still using the Repeater $9 \mathrm{~A} \cdot{ }^{95}$ As well as this realisation, the sectional engineer's visit allowed him to closely examine Harris's personal amplifying device and draw a diagram outlining its design which he then sent to the engineer-in-chief as part of a special report on Harris's design. He explained:

For his private use the subscriber has an amplifier with associated microphone giving an output much in excess of our instrument. I have called for a special report on this private apparatus and may be able to adapt our amplifier to work in conjunction with it. No mention of this has of course been made to the subscriber. ${ }^{96}$

The Post Office explicitly decided not to inform Harris that they were compiling a special report on his apparatus as this, alongside the absence of patent protection, allowed its engineers to reproduce his design without his knowledge or consent. There was precedent within the Post Office of appropriating designs in this way, as can be seen in the case of the deaf electrical engineer Oliver Heaviside and his interactions with the Post Office in the 
late nineteenth century. ${ }^{97}$ Like Harris, Heaviside had hearing loss, worked on improvements to telephony (long-distance telephony) and did not protect his inventions because of his altruistic principles. Heaviside also had an acrimonious relationship with the Post Office and his 'open approach' to 'do good to my fellow creatures' was 'in part a reaction against attempts by William Preece, the Chief Electrician at the UK Post Office, to suppress his theories of longdistance telephony.98 Because Heaviside did not patent his innovation and took the same moral stance as Harris regarding the need to share inventions, the Post Office was able to adopt his invention without according Heaviside any recognition. ${ }^{99}$ Like Heaviside, Harris was an innovator but he was also a user. Harris's design was clearly very personal and tailored to his individual body and needs. The disparity between the Post Office's measured approach to the amplified telephone and Harris's personally embodied design was at the heart of the tensions that developed in this case. Harris's correspondence with the Post Office is especially revealing of such inconsistencies between institutional expectations of hearing and user expectations of amplification, as well as incongruities inherent in Post Office policies regarding their 'Deaf Subscribers'. Furthermore, his case highlights how users drew upon personal experience and bodily knowledge to improve the telephones in ways that the Post Office could not.

Although it was created for an individual need, Harris's device was superior to the Post Office's device in providing greater amplification as well as being uniquely suitable for his exact level of frequency loss. The Repeater 9A, the only amplified telephone that could be used in Harris's area, utilised just one single thermionic valve and one dry battery, whereas Harris's circuit greatly increased amplification because it used a triode valve and a pentode valve. The resulting amplification was so great that Post Office engineers reported that it could not be tolerated by a person with normal hearing and that they could not risk putting on the headphones to test it. ${ }^{100}$ Although his modified device was perfect for him, it was not accepted by the Post Office because it was not standardised and could not be measured by their equipment or engineers. The level of amplification was perfect for Harris, however, and this aspect of his invention can be usefully considered as a form of embodied knowledge, a type of knowledge intimately linked to a person's specific nature. ${ }^{101}$

Knowledge of the degree of amplification and tone control needed for Harris to hear on the telephone was something that only he could gauge. His body and his hearing allowed him to mediate the level of amplification in a way that the Post Office engineers physically could not. However, the fact that the Post Office reproduced his amplifier instead of allowing him to use his 
own indicates that the kind of embodied knowledge gained through disability was not considered legitimate by the institution. Indeed, the decision to move away from equipment designed using personal, embodied knowledge of sound through individual sensory judgement was reflected in larger movements towards standardised measurements of sound in the 1920s and 1930s, which will be explored in the next chapter. Such technocratic approaches represented a developing dichotomy between the divergent needs of users with hearing loss and the decibel-based standards of the Post Office. Although the Post Office admitted that Harris's device provided greater amplification, this dichotomy proscribed Harris's embodied invention as an unmeasurable and unpatented device. His invention could not be tested or trusted by the Post Office engineers. In the context of Harris's innovation, his body was problematised as a reliable source of knowledge because it could only be measured in individualistic terms. Yet it was his personal insight that allowed the Post Office to improve its amplified telephone service. It profited from his bodily knowledge by turning his insight into a commodity that could be exploited for commercial gain. Mills has pointed out that disability can be used in this way to provide a source of technical innovation, but that in the case of telephony and hearing loss, this connection is far deeper and more complicated than simple appropriation. ${ }^{102}$ The kind of technical insights that Harris could provide were not welcomed by the Post Office Telecommunication Department, which was trying to provide a standard telephone for the deaf that could be used by a typical 'Deaf Subscriber'.

The Post Office was protected from accusations of plagiarism in cases like this because its work was under Crown copyright, which gave greater protection and secrecy than a patent. Established in 1911, this protected any works created under any government department. ${ }^{103}$ Despite the fact that neither the Post Office nor Harris patented their amplified telephones, there were thirteen amplified telephony patents taken out by private entrepreneurs between 1921 and 1935, even though it was illegal to use them. ${ }^{104}$ Clearly, the problem of hearing over the phone was widespread and there was felt to be a need for it to be addressed. Private hearing aid companies including Amplivox, Multitone and Ossicaide all invented systems of listening to the telephone via a hearing aid through induced currents. ${ }^{105}$ The Post Office viewed private hearing aid firms offering telephonic assistance as a threat to their control and refused to sanction the use of such hearing aid couplers with their telephones. Indeed, it was concerned to such an extent that it advocated completely prohibiting private hearing aids with couplers as illegal infringements, as they had done with Harris's equipment. However, as these devices did not have a physical attachment to the telephones, the Post Office could not completely ban them 
as they had done with Harris's device, though they were still able to moderate their use.

After the case with Harris was resolved, the Post Office accelerated the development of its telephone for 'Deaf Subscribers' so that a device with greater amplification could be used as standard in all areas. This became known as the Repeater $17 \mathrm{~b}$ and was $13.5 \mathrm{db}$ louder than the $17 \mathrm{a}$ and included a tone control button for users like Harris who needed different frequencies amplified (see Figure 3.4).

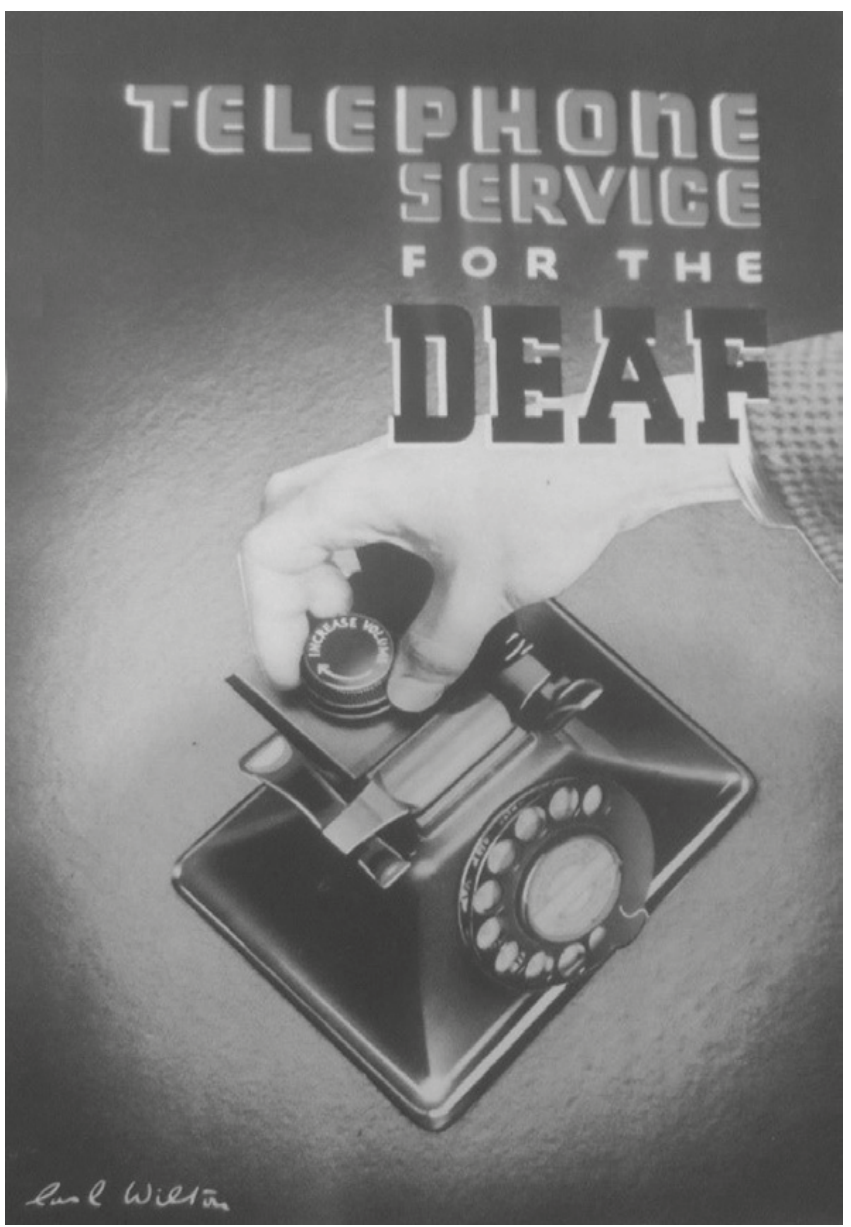

Figure 3.4 'Telephone Service for the Deaf', 1938 
Harris was able to use this new telephone even though (according to the Post Office) he was 'extremely deaf'. Categorical terminology like this is a recurring difficulty in such cases, revealing tensions regarding how best to decide who was 'too deaf' to use the telephone, who was 'hard of hearing' and what to call these two groups. The Post Office described those who could use the telephone with extra amplification as 'hard of hearing' and those who could not as 'deaf' or 'extremely deaf'. Categorising deafness in this way meant that the condition of hearing or deafness changed with the improvement of technology rather than through any improvement in hearing. When Harris was able to use the more powerful telephone, he was re-categorised as hard of hearing rather than 'extremely deaf', although his medical level of hearing was unchanged. Categorisation depended on the efficacy of the technology rather than on the telephone user's level of hearing.

The improved amplified telephone (the Repeater 17B) cost $£ 1$ more (rental per annum) than the older model. This was not acceptable to users who felt they were being increasingly penalised for their hearing. For example, Mr Mousley, director of the Birmingham company Charles Winn \& Co., was outraged at the expense of the more powerful amplified telephone, and refused 'to pay any additional rental in respect of it', and threatened in a letter of July 1938 that if the matter was not given immediate attention he would take the case up with the Postmaster General. ${ }^{106} \mathrm{He}$ was especially irate at having to pay $£ 3$ at his private residence as well as on his business line and in response he withheld his telephone rent, starting on the 9 November $1938 .{ }^{107}$ This was an effective strategy. The Telecommunications Department were concerned and asked the Birmingham telephone manager: 'if it is possible to accede to his application. Messrs. Winn \& Co. are good customers, the account being in the neighbourhood of $£ 50$ per quarter. ${ }^{108}$

The Sales Department therefore allowed Mr Mousley a three-month trial of the improved amplifier, free of charge. However, their real hope was: at the end of that time [to] be able to convince the subscriber that the difficulty that he is experiencing is not due to the service but rather to his affliction. ${ }^{109}$ The sales superintendent in Birmingham also pointed out to Mr Mousley that 'there were a good number of amplifiers existing in the Birmingham telephone area and that he was the only subscriber that complained." ${ }^{110}$ This statement reveals that the amplification service was fairly popular at this time, although it is less clear whether this was due to widespread deafness or particular localised problems with the telephone system in Birmingham. However, at the heart of this case was contestation of the measurement and categorisation of deafness rather than the efficacy of the amplifying technology. For instance, Mr Mousley wrote: 'I resent very much having to pay for an amplifier at all considering 
the reason is not really my deafness but the inefficiency of some of the Post Office lines and functions.' 111 This was contested by the Post Office, especially when the traffic superintendent discovered that Mousley had started to wear hearing aids for ordinary conversation:

Mr Mousley now regularly uses special apparatus with which to carry on his normal business conversation. It consists of a headgear receiver connected to a portable valve amplifier, the power being drawn - I am told - from a 2 volt dry battery. The subscriber carries on a conversation apparently without difficulty when wearing the headgear; but in my opinion he is deafer than ever when not utilising this apparatus. ${ }^{112}$

This dialogue provides an example of what I described in Chapter 2 as epistemic injustice of a kind specific to the disabled. ${ }^{113}$ The specialist knowledge that the disabled have regarding how their bodies' needs are best met has been consistently undervalued, perpetuating a cycle of injustice which undermines the knowledge claims of the disabled. ${ }^{114}$ Not only was the new visibility of Mr Mousley's hearing loss used to discredit his claims about his inadequate telephone provision, his knowledge about the kind of hearing-assistive technology which could have helped him was disregarded.

It is unclear whether this unusual headgear design was provided by a private company or if it was an invention of Mr Mousley's. His company, Charles Winn \& Co., did specialise in manufacturing valves (and sewing machines and fire appliances), so he would have had easy access to such materials. ${ }^{115}$ Indeed, this kind of innovation was not unusual during this period, and reports of similar designs were outlined in the British Medical Journal in 1935. For example, Dr Phyllis Kerridge reported on 'Aids for the Deaf' and explained: 'Amateur wireless constructors have often designed very satisfactory circuits for themselves or their relatives by the method of trial and error. ${ }^{116}$ She gave two examples to illustrate such home-made hearing aids, such as one designed by a laboratory assistant

so deaf that unaided he could not hear conversation at all. He has a quadruple microtelephone instrument, and wears the microphone hidden under his overall. With this help conversation is possible, and he is able to take instructions and keep his job. He uses one battery a week, and finds that the old ones will light his bicycle lamp after they are no good for the hearing aid. ${ }^{117}$

This example gives us a fascinating insight into the everyday struggles of those trying to use telephone technology to overcome their hearing loss during this period. It is striking how often such apparatus was characterised by user 
modification. Another example given in the same paper was of an amateur wireless constructor who had

made himself a valve amplifier set, incorporating a tone control, with which he can hear conversation quite easily. He keeps two sets in working order by him, as he is quite incapacitated without one. He finds the tone control satisfactory for clear understanding, and a further advantage is that he can tune out the unpleasant qualities of voices which he disliked in his hearing days. ${ }^{118}$

This kind of selective hearing and use of hearing aids as a means of power and control has also been noted in the use of acoustic aids such as ear trumpets, which could be effectively manipulated to signal boredom with the conversation and, arguably, to demonstrate control over the conversation. ${ }^{119}$

As the above cases outlined, the development of amplified telephony was marked by tensions between the Post Office's monopoly and the duty it felt to provide a service to citizens with varying hearing needs. The amplified telephone was constructed by the Post Office in a process marked by user input and corresponding design modifications. The selection of cases I have chosen to focus on in this chapter are those which contained more detailed information or forced through specific changes. However, there are many other examples in the archives of such user input, which continued long after the interwar period. For example, on 20 March 1954, William S. Clark wrote to telephone headquarters to point out that 'the present mouthpiece fitted usually to telephone handsets is unsuitable for use for people using deaf-aids.' ${ }^{120}$ He explained that

the usual mouthpiece has a cupped shape. When using a deaf-aid, the earpiece of the handset has to be placed against the deaf-aid microphone. The 'mike' is usually worn on the chest, therefore when using a deaf-aid, the handset is used upside down. This means that the mouthpiece is turned away from the mouth of the speaker. ${ }^{121}$

To illustrate the problem and his suggested solution (changing to standard usage of mouthpiece no. 18) he included a drawing which vividly illustrated the problems he faced in his everyday interactions with telephony (see Figure 3.5). This was another example of user appropriation of technology that had not been anticipated by the Post Office and could not be approved. The engineering department explained that the alternative mouthpiece often led to transmission loss 'during normal use' and argued that 'we should not encourage its use merely for the sake of a slight gain in convenience, and perhaps in relative efficiency, when the handset is used upside down by a deaf person, at the expense of the certain transmission loss to all normal users. ${ }^{122}$ 


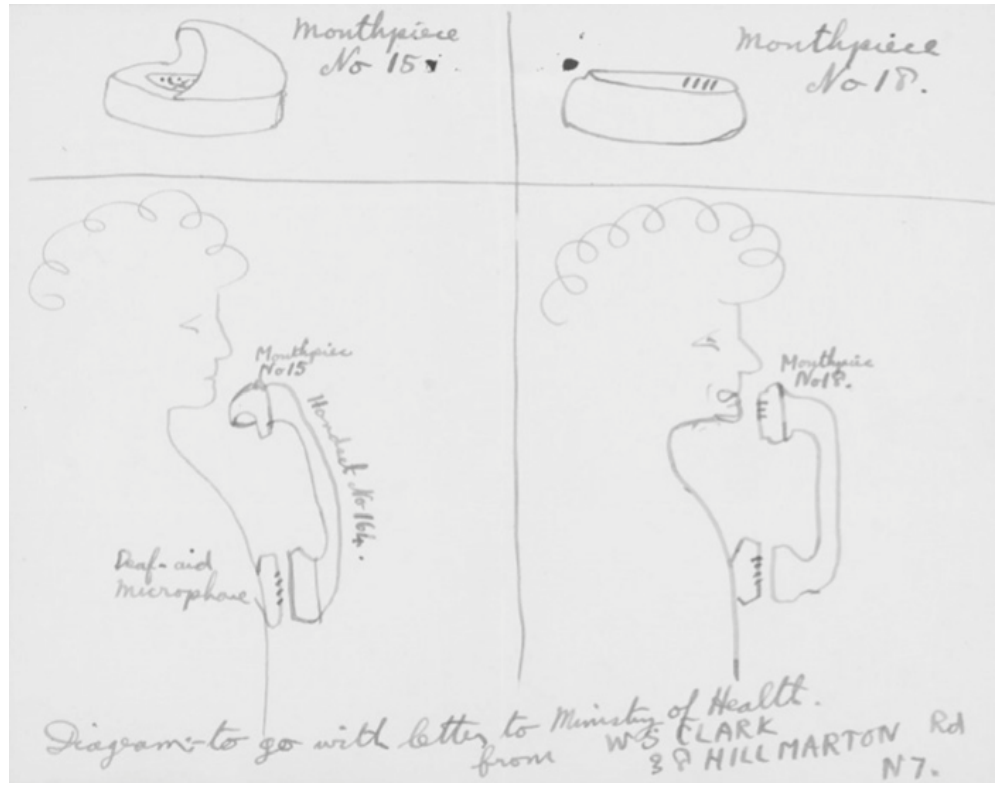

Figure 3.5 'Suggestion that a flat mouthpiece, instead of the normal cupped one, should be provided to facilitate the use of a telephone in conjunction with a deaf aid worn on the chest'. Letter from W. S. Clark to Telephone Headquarters, 20 March 1954

These kinds of suggested improvements to amplified telephony were hampered due to the complexities of matching individual user needs with the Post Office institutional set-up and the way in which individuals' lived experience of hearing conflicted with the Post Office's desire for standardisation. As a government department, standardisation was fundamental to the Post Office's wider ethos regarding its customers, as providing the same service to all was integral to its democratic position.

The aspiration for standardisation was a built-in component of telephone networks more generally and its pursuit was partially driven by technical necessity. Today, telephony is often used by historians of technology to exemplify how a device can create a network effect because the desirability of the telephone directly correlated to the number of subscribers to the same system. ${ }^{123}$ However, there were tensions between different exchanges and their networks in the era prior to nationalisation in Britain. For example, local subscribers benefited more from local exchanges, and public exchanges were 
more expensive for telephone companies to build than private wire systems. ${ }^{124}$ But different exchanges that offered different types of connection did not fit with the Post Office's nationalised service ethos. Similarly, though the American Telephone and Telegraph company (henceforth AT\&T) did not have a government-mandated monopoly, it still exerted its domination on the lines of communication in a way that has been described as a form of 'American socialism', exemplified by the AT\&T slogan: 'One policy, One system, Universal service.' ${ }^{\prime 25}$

In opposition to this will towards standardisation, the Post Office's first amplified telephone did not supply everyone with a telephone that they could use: those with hearing loss too great for this Post Office machine were thus redefined as living on the threshold of 'deafness'. This meant that users had to actively engage with the technology on an individual level to pressure the Post Office to create an amplified telephone model that fitted with their level of hearing loss (volume amplification) as well as their type of hearing loss (frequency adjustment). Thus, telephone companies created standards of normal hearing outside of the medical sphere. As Mara Mills has explored, this situation was paralleled through the remit of the private AT\&T telephone company. Although no single nationalised company in the United States held a state-sanctioned monopoly over the telephone service as in Britain, AT\&T held a practical monopoly over the telephone system in the USA at this time. While AT\&T's monopoly was not legislated by the government, in practice it controlled the telephone service and fought off any competition to maintain its position. One seminal example of its monopolistic powers comes from the 1949-68 case of The Hush-A-Phone Corporation v. The United States, which centred on the Hush-A-Phone, a device which was attached by the telephone user to the telephone to improve audibility. This was considered by AT\&T to be an illegal attachment that infringed on its monopoly and AT\&T went to court to successfully ban the Hush-A-Phone device. ${ }^{126}$ In contrast the Post Office were advised not to press charges in a similar situation involving private hearing aid companies using couplers to link hearing aids with their telephones on the grounds that these companies were not using physical attachments. This was an unusual decision because the Post Office operated a strict blanket ban on any private apparatus on their lines. However, the Post Office did supply amplified telephones for their subscribers with hearing loss throughout the interwar years, and this was a marked divergence from AT\&T's policy, perhaps indicating a somewhat more inclusive approach towards those with hearing limitations wrought by UK welfare-state ideologies. 
AT\&T's specialisation in hearing loss over general telephone lines contrasted with their refusal to provide customers with a telephone system suitable for the deaf, and this became the focus of a widespread campaign in the late 1960s. ${ }^{127}$ However, Bell Laboratories did work with the US Public Health Service in 1936 to test the hearing of 9,000 adults using their audiometer. ${ }^{128}$ This allowed for testing of the nation's audiological health, as well as providing AT\&T with more comprehensive data to set the standard of normalcy. Mills explains that AT\&T's study into speech and hearing was wide-ranging and comprehensive, designed for the most efficient telephone service: 'in the hopes of connecting its system to the average ear, and in turn exploiting that ear's limitations to establish the requisites for "intelligible" transmission across imperfect lines (and later still, to transmit compressed speech).'. ${ }^{129}$ However, Mills points out that because such surveys sought to identify normal hearing and discounted older people and people with hearing limitations, the resulting average was not the norm but rather the upper quartile of the norm. ${ }^{130}$ Like the Post Office, AT\&T sought the average of pre-identified normal hearing rather than representing the true variability of hearing ability in the population.

The different contexts of nationalisation versus private development meant that the standards in the UK and the USA for normal hearing (the zero line of the audiometer) were different until 1964. ${ }^{131}$ This crucial point demonstrates the subtle influence that the classification systems used in technologies like the telephone have on our conception of normal functioning. Comparing AT\&T's services for those with hearing loss to the British Post Office's service shows how the drive for standardisation was impacted by both local contexts and commercial imperatives. Mills has demonstrated that there were multiple connections between deafness and the development of telephony at AT\&T. First, she illuminates that people with hearing loss were activists, and engaged with AT\&T in the pursuit of rehabilitation devices. ${ }^{132}$ Second, in turn, the novel concept of deafening was appropriated by AT\&T as both a useful category and an applied term for telephone engineers. Third, AT\&T's audiometric experiments and surveys on levels of normal hearing were utilised in medicine and used to define the 'normal' standard of hearing for the audiograms utilised in hearing tests. ${ }^{133}$ That the US norm differed from the UK norm in the interwar period was demonstrated by the much larger (though still not representative) sample used by AT\&T to create the standard. Despite these differences, both the USA and the UK telephone companies sought to manage the variability of hearing through mechanisms that promoted a narrow average standard as representative of the norm. 


\section{Conclusion: the standardisation of normal hearing}

Designating the standard of normal hearing in this narrow mechanistic fashion with idealised averages meant that users were forced to engage with the Post Office to access telephony. User activism was a key force for change in this respect, as aspirational users forced the Post Office to create specialised and affordable technology to allow them to access telephony. As a result, the Post Office became the de facto experts in hearing-assistive technology during the interwar period. However, as we will see in the next chapter, data on the expected parameters of 'normal hearing' as the Post Office defined it was gathered by the expanding field of audiometry, which used telephones to measure ears literally through audiometers. ${ }^{134}$ Clinicians used the telephone in the form of the audiometer to create standardised levels of normal hearing and defined deviance from that norm as deafness that could be corrected with appropriate hearing aids.

There is a clear feedback loop here, between the engineering of the telephone system and the standardisation of hearing integral to audiometric calibration. This loop was interrelated, working both ways, as deaf ears were used to improve the telephone system just as the telephone system was used to simultaneously define and 'improve' deaf ears. Moreover, the normative standards embodied in such instrumentation became increasingly invisible as they were perpetuated. During the interwar years, the state of being deaf or hearing became defined through the ability, or otherwise, to use certain kinds of telephone - both literally in the form of the audiometer and socially through the ability to engage with the telephone. To retain their hearing identity and not be categorised as deaf, with the corresponding stigma that invoked, people with hearing loss engaged with amplified telephones. Through such interactions, telephony was used as a tool in the categorisation of disability and, in turn, telephone users modified the technology to fit their personal needs, experiences and identities. Yet this promise of improvement was not realised in practice because the Post Office's standard amplified telephone model did not reflect either the significant diversity of users' hearing or the variability of hearing loss. The standardisation of normal hearing and the categorisation of the deafened was therefore both facilitated and created in line with the priorities of the British Post Office's telephone system. This analysis demonstrates the fluctuating and contingent thresholds of normalcy construction and reveals how deafness was socially and technologically constructed in interwar Britain.

As Stuart Blume has elucidated: 'the user "inscribed" in a technology, imagined by its designers, may not correspond with real users in the real world. ${ }^{135}$ Considering user experiences of disability technology often reveals 
discrepancies between the designed ideal user and the disabled user in real life. Indeed, there is no such thing in real life as the imagined ideal user. However, in the case of the disabled user, the frequent imbalance of power between designer and user can heighten these discrepancies. Analysis of the way these users adapted the telephone to suit their individual needs corresponds to studies concerned with deaf users' relationships to prostheses, especially the way they have been adapted, modified and controlled. ${ }^{136}$ Non-use was also a response, and STS scholar Sally Wyatt has clarified the importance of this by dividing this category into four sub-groups: resisters, rejecters, the excluded and the expelled. ${ }^{137}$ I add users of the telephone with hearing loss into this analysis as aspirational users who wanted to use the telephone and used a variety of techniques to gain access. By following the individual experiences of users, I demonstrate that the telephone was used as a prosthetic to enable users to pass as 'hearing'.

While a growing number of historians of disability examine the multiple ways in which social contexts shape and define disability and ability, this analysis provides a new perspective on the fluid boundaries between hearing and deafness created by the telephone. This neglected episode of early twentieth-century telephony redefines the relationship between technology, communications and disability, and broadens our historical understanding of deafness. Science and technology studies have decisively demonstrated that technologies are not neutral, but rather are shaped by the cultures, contexts and the actors that make them. By focusing on the forces and norms which enact technologies we reveal the socio-cultural and anthropological decisions embedded within them. This is an issue of central concern to disability studies because of the normativising power of technologies like the artificial ear. As this chapter has demonstrated, technology's development is interlinked to the classification and enforcement of normative categories embedded in big data. To explore these topics more thoroughly, in the next chapter I discuss the development of audiometry and its role in shaping the social and technological construction of normalcy.

\section{Notes}

1 Lecture by Professor William Rutherford, 'The Sense of Hearing: A Lecture by Professor Rutherford M.D., F.R.S., Professor of Institutes of Medicine in the University of Edinburgh', in Acoustics: Music, Lord Kelvin's Collection, 1886. University of Glasgow Special Collections, Glasgow, Kelvin 11920 - 1892.

2 Ibid., p. 20.

3 Ibid., p. 21. 
4 Enns, A., 'The Human Telephone: Physiology, Neurology, and Sound Technologies', in D. Morat (ed.), Sounds of Modern History: Auditory Cultures in 19th-and 20th-Century Europe (New York: Berghahn, 2014), pp. 46-68, p. 62.

5 Parts of this chapter were originally published in McGuire, C., 'The Categorisation of Hearing Loss in Inter-War Telephony', in G. Balbi and C. Berth (eds), Special Issue: 'A New History of the Telephone', History and Technology (2019), 35:2, 138-155.

6 Pinch, T., and Bijker, W. E., 'The Social Construction of Facts and Artifacts: Or How the Sociology of Science and the Sociology of Technology Might Benefit Each Other', Social Studies of Science, 14:3 (1984), 399-431. See also Bijker, W. E., Of Bicycles, Bakelite and Bulbs: Towards a Theory of Sociotechnical Change (Cambridge, MA: MIT Press, 1995) and Pinch, T., and Oudshoorn, N. (eds), How Users Matter: The Co-Construction of Users and Technology (Cambridge, MA: MIT Press, 2005).

7 Kay, M., 'Inventing Telephone Usage: Debating Ownership, Entitlement and Purpose in Early British Telephony' (PhD dissertation, University of Leeds, 2015).

8 Esmail, J., Reading Victorian Deafness: Signs and Sounds in Victorian Literature and Culture (Athens: Ohio University Press, 2014).

9 These examples are from tenders submitted to the Ministry of Pensions by hearing aid firms between 1924 and 1939. The National Archives, Kew, London (henceforth TNA), 'Supply of Electrophones: 1924-1926'. TNA, PIN 38/450; 'Supply of Electrophones: 1926-1929'. TNA, PIN 38/451; 'Supply of Electrophones: 19381939'. TNA, PIN 38/452.

10 Enns, 'The Human Telephone', p. 60.

11 Campbell-Smith, Masters of the Post, p. 169.

12 Ibid., p. 271.

13 The 1869 Telegraph Act granted this monopoly over communications and it was confirmed in 1880 that this Act included telephony even though the telephone had not been invented when the Act was first conceived. See Campbell-Smith, Masters of the Post, p. 193.

14 Perry, C. R., 'The British Experience', in I. D. Pool (ed.), The Social Impact of the Telephone (Cambridge, MA: MIT Press, 1977), pp. 69-96.

15 For an overview of radio and the BBC's impact on accent standardisation see Schwyter, J. R., Dictating to the Mob: The History of the BBC Advisory Committee on Spoken English (Oxford: Oxford University Press, 2016).

16 Thaczyk, V., 'Archival Traces of Applied Research: Language Planning and Psychotechnics in Interwar Germany', Technology and Culture, 60:2 (2019), 564-595, p. 573.

17 In this book I use the term hearing loss to more accurately reflect the experience of those using amplified telephones during this period as belonging to the new category of those 'deafened' from age or noise-induced hearing loss, who have experienced this change as a loss and tried to recover hearing through technology.

18 Telegraphy, visual signalling and motorbike couriers were considered more important and written proof or an orderly was regarded as more secure. Telephones were only used as Morse receivers or for communicating with surveillance balloons. Bridge, M., and Pegg, J., Call to Arms: A History of Military Communications from the Crimean War to the Present Day (Tavistock: Focus Publishing, 2001), p. 39-43. 
19 Ibid., pp. 35-40.

20 Hall, B. N., 'The Life-Blood of Command? The British Army, Communications and the Telephone, 1871-1914', War and Society, 27:2 (2008), 43-65.

21 Ibid., p. 62.

22 Ogilvie, A., 'Reply: Complimentary Dinner to Sir Andrew Ogilvie', Post Office Electrical Engineers' Journal, 12 (1920), 70-81, p. 71.

23 Juniper, D., 'The First World War and Radio Development', RUSI Journal, 148:1 (2003), 84-89.

24 Ogilvie, 'Reply', p. 72.

25 Haigh, A., 'Post Office War Research. “To Strive, To Seek, To Find”: Post Office Engineering Research from the Experimenting Room to “Dollis Hill”, 1908-1938' (PhD dissertation, University of Leeds, forthcoming).

26 The 'Acousticon' transmitter was originally designed as a hearing aid but was developed into the hypersensitive transmitters used by the Post Office. See ibid.

27 Ogilvie, 'Reply', pp. 70-81.

28 Bridge and Pegg, Call to Arms, p. 176.

29 Cruikshank, W., 'Editorial Notes and Comments', Post Office Electrical Engineers' Journal, 12 (1919), 173-178, p. 175.

30 Such appropriation of military equipment for civilian use has been explored by Mara Mills in relation to the miniaturisation of hearing aids in the context of the Second World War. See Mills, M., 'When Mobile Communication Technologies Were New', Endeavour, 33:4 (2009), 140-146.

31 Bridge and Pegg, Call to Arms, p. 42.

32 'Editorial: The Telephone Repeater', Post Office Electrical Engineers' Journal, 12 (1919), 7-8, p. 7.

33 Ibid., pp. 7-8.

34 Hall, 'The Life-Blood of Command?', p. 46.

35 Arapostathis, S., and Gooday, G., Patently Contestable: Electrical Technologies and Inventor Identities on Trial in Britain (Cambridge, MA: MIT Press, 2013).

36 Cruikshank, 'Editorial Notes and Comments', p. 79.

37 See Gooday and Sayer, Managing the Experience of Hearing Loss; Virdi [VirdiDhesi], J., 'Curtis's Cephaloscope: Deafness and the Making of Surgical Authority in London, 1816-1845', Bulletin of the History of Medicine, 87:3 (2013), 347-377.

38 Branson and Miller, Damned for their Difference.

39 See ch. 6 of Gooday and Sayer, Managing the Experience of Hearing Loss.

40 In 2011, the charity became Action on Hearing Loss to better reflect its target users.

41 The National Benevolent Society for the Deaf, 'Hon. Central Secretary's Report, 1918-1919'. UCL Ear Institute and Action on Hearing Loss Library, London (hereafter AOHL). Emphasis in original.

42 The National Benevolent Society for the Deaf, 'Annual Report 1919'. AOHL.

43 The National Benevolent Society for the Deaf, '11th Annual Report 1929'. AOHL. 
44 National Bureau for the Promotion of the General Welfare of the Deaf, 'Report of the Third Annual Meeting, Wednesday November 11th 1914'. AOHL. See also National Bureau for the Promotion of the General Welfare of the Deaf, reports of annual meetings between 1911 and 1922.

45 Gooday and Sayer, Managing the Experience of Hearing Loss, p. 27.

46 Hendy, D., Noise: A Human History of Sound and Listening (London: Profile Books, 2013), p. 36.

47 Van der Kloot, W., 'Lawrence Bragg's Role in the Development of Sound-Ranging in World War I', Notes and Records of the Royal Society, 59:3 (2005), 273-284, p. 278.

48 Enke, J., 'War Noises on the Battlefield: On Fighting Underground and Learning to Listen in the Great War', German Historical Institute London Bulletin, 37:1 (2015), 7-21.

49 Also see Hurst, A. F., Letter to the Editor, 'War Deafness', The Lancet, 192:4955 (1918), 218-219, and Turner, W. A., 'Remarks on Cases of Nervous and Mental Shock: Observed in the Base Hospital in France', British Medical Journal, 1:2837 (1915), 833-835.

$50 \mathrm{Li}$ and Mills, 'Vocal Features', p. 136.

51 Ibid., p. 152.

52 This is also a problem for anyone with a non-standard accent. Being both Scottish and a woman I find voice recognition nigh impossible and once memorably accosted a gentleman passing me on Woodhouse Lane in Leeds and exhorted him to speak my registration number into my mobile so I could use the voice recognition system to park my car as I was running late for a job interview. Comedians Iain Connell and Robert Florence vividly demonstrated this issue in 'Voice Recognition Elevator in Scotland' from the BBC Scotland sketch show Burnistoun, which ends with two frustrated men stuck in a voice-activated elevator screaming 'Eleven' at an unyielding microphone. https://web.archive.org/watch?v=sAz_UvnUeuU. Accessed July 2019. See also, Bajorek, J. P., 'Voice Recognition Still Has Significant Race and Gender Biases', Harvard Business Review: Technology (10 May 2019). https://hbr.org/2019/05/voice-recognition-still-has-significant-race-and-genderbiases. Accessed July 2019.

53 The National Telephone Company, Engineer in Chief's Department, 'The Selection of Suitable Substitutes for the Human Voice and Ear in Transmission Testing,' 26 February 1908, p. 29. BTA, TCB 22 T0339.

54 The Post Office kept the structure of the NTC and inherited all its outdated equipment because the company stopped investing in its stock when they realised that they would have to hand it over to the government. The Post Office also had to invest enormous amounts of material and research in the war, which would account for this gap in research and development.

55 Alridge, A. J., and West, W., 'Measurements of the Acoustical Impedance of Human Ears', Research Report No. 4697, Research Station at Dollis Hill, May-September 1928, p. 2. BTA, TCB 422 04697. Acoustical impedance was defined in the report 
as 'the ratio of alternating pressure to alternating rate of volume displacement, i.e. if a piston of area is vibrating with velocity $\mathrm{v}$ and a pressure $\mathrm{p}$ per unit area is developed at its surface due to its contact with the medium (air)'.

56 Ibid., p. 15.

57 Alridge, A. J., and West, W., 'An Artificial Ear', Research Report No. 4946, Research Station at Dollis Hill, 21 October 1929, p. 7. BTA, TCB 42204946.

58 Ibid., p. 8.

59 Ibid.

60 Ibid.

61 The Post Office tested hearing aids at the Dollis Hill Research Station on behalf of the National Physical Laboratory and in conjunction with the NID. See Wharry, H. M., and Crowden, G. P., 'Correction of Hearing Defects', British Medical Journal, $1: 3727$ (1932).

62 Plans for an NHS hearing aid began in 1947. The Medresco was a contraction of 'Medical Research Council', and this name has led to overemphasis on the MRC's role in its creation, with attendant erasure of the work of the Post Office. Instead of designing a new amplified telephone alongside the NHS hearing aid, the Post Office engineers designed an adaptor to link the new hearing aids with telephone receivers. This would allow users to link into any telephone and not just their home sets. See McGuire and Carel, 'The Visible and Invisible'.

63 Weber, 'Manufacturing Gender', p. 240.

64 Braun, Breathing Race into the Machine, Introduction, p. xxvi.

65 Ibid., p. xvii.

66 Smith Brothers \& Co., Letter to The Engineer, London Telephone Service East Exchange, 12 January 1922. BTA, POST 33/1491C.

67 Kay, 'Inventing Telephone Usage'.

68 Smith Brothers \& Co., Letter to The Engineer. His reference to the NTC is interesting as the government takeover of the telephone system was generally popular with the British public, who wanted a regulated, cheaper telephone service. However, a regulated government service may not have been the best outcome for those who had specific needs that a private company might have provided for. The reference to using a private maker related to the threat of private hearing aid companies.

69 Ibid.

70 Hong, S., Wireless: From Marconi's Black-Box to the Audion (Cambridge, MA: MIT Press, 2001), pp. 163-167.

71 Ibid., p. 9.

72 Letter from Superintending Engineer (London Engineering District) to the Engineer in Chief, 30 January 1922. BTA, POST 33/1491C.

73 Secretary for the Engineer in Chief, Memorandum dated 10 March 1922. BTA, POST 33/1491C.

74 Note to the Engineer in Chief, 1922, from Superintending Engineer. BTA, POST $33 / 1491$ C. 
75 Memorandum attached to the above note. BTA, POST 33/1491C.

76 Perry, 'The British Experience', p 85.

77 Ibid.

78 Rosenberg, N., Exploring the Black Box: Technology, Economics, and History (Cambridge: Cambridge University Press, 1994), p. 5.

79 Memorandum from Accounts to the Superintending Engineer, 23 October 1924. BTA, POST 33/1491C.

80 Memorandum from the Engineer in Chief (Accounts) to the Superintending Engineer Concerning Insuring the Repeater 9A, 23 October 1924. BTA, POST 33/ $1491 \mathrm{C}$.

81 Correspondence between H. C. Buckley and Postmaster General, 19 October 1928. BTA, POST 33/1491C.

82 Ibid.

83 Correspondence between Secretary and the Postmaster General and H. C. Buckley, December 1928. BTA, POST 33/1491C.

84 Correspondence between H. C. Buckley and Postmaster General, 12 December 1928. BTA, POST 33/1491C.

85 Ibid.

86 McGuire, C., 'Inventing Amplified Telephony: The Co-Creation of Aural Technology and Disability', in C. Jones (ed.), Rethinking Modern Prostheses in AngloAmerican Commodity Cultures, 1820-1939 (Manchester: Manchester University Press, 2017), pp. 70-90, p. 74.

87 'Aids to Telephone Reception for Partially Deaf Subscribers', Research Report No. 9150, Post Office Research Station, 21 April 1936, precis. BTA, TCB 42209150.

88 Kerridge, P. M. T., 'Aids for the Deaf', British Medical Journal, 3886:1 (1935), 13141317.

89 Esmail, Reading Victorian Deafness. On passing, see Cureton, A., 'Hiding a Disability and Passing as Non-Disabled', in A. Cureton and T. E. Hill, Jnr (eds), Disability in Practice: Attitudes, Policies and Relationships (Oxford: Oxford University Press, 2018), pp. 15-32.

90 For an overview of d/Deaf history and the history of hearing loss see Gooday and Sayer, Managing the Experience of Hearing Loss and Davis, Enforcing Normalcy.

91 Brune, A., and Wilson, D. J., Disability and Passing: Blurring the Lines of Identity (Philadelphia: Temple University Press, 2013).

92 For consideration of how this affects user rejection of assistive technology, see McGuire and Carel, 'The Visible and Invisible'.

93 'Aids to Telephone Reception'.

94 For the full article, which contains more details of the Harris case, see McGuire, 'Inventing Amplified Telephony'.

95 It could be used in CB and automatic areas but not in the Magneto and CBS areas. At this time, the telephone service was divided into service areas which were 
abbreviated according to the system they used. They were either CB (central battery working), CBS (central battery signalling), Magneto (using crank generators) or the Automatic exchanges, which were becoming more common after 1920 . CBS and Magneto were old and outdated systems by the 1930s, which explains why the newer amplified telephones did not work in areas using these systems. They also had batteries at their end rather than at the exchange, which would have further complicated adding extra apparatus.

96 W. G. Luxton, Bristol Sectional Engineer, to the District Manager, 5 August 1936. BTA, POST 33/1491C.

97 Arapostathis and Gooday, Patently Contestable, pp. 106-110.

98 Ibid., p. 107.

99 Ibid., p. 110.

100 Letter from W. G. Luxton, Sectional Engineer, to the Superintending Engineer, 28 September 1936. BTA, POST 33/1491C.

101 Fourcade, M., 'The Problem of Embodiment in the Sociology of Knowledge: Afterword to the Special Issue on Knowledge in Practice', Qualitative Sociology, 33:4 (2010), 569-574, p. 571.

102 Mills, M., 'Deafening: Noise and the Engineering of Communication in the Telephone System', Grey Room, 43 (2011), 118-143.

103 Green Paper, 'Crown Copyright in the Information Age', Section 2.5 (1998). www.opsi.gov.uk/advice/crown-copyright/crown-copyright-in-the-informationage.pdf. Accessed April 2019.

104 Accessed using Directory of European Patents, European Patent Office. http:// worldwide.espacenet.com/mydocumentslist?submitted=true\&locale=en_EP. Accessed April 2019.

105 Letter from Edwin Stevens/Amplivox to the Chief Engineer, 7 July 1938. BTA, TCB 2/171-2/172.

106 Letter from Mr Mousley to Telecommunications Department, 28 July 1938. BTA, TCB 2/171-2/172.

107 Letter from Charles Winn \& Co., 9 November 1938. BTA, TCB 2/171-2/172.

108 Letter from Telecommunications Department, 2 November 1938. BTA, TCB 2/ $171-2 / 172$.

109 Letter from Sales Department, 30 July 1938. BTA, TCB 2/171-2/172.

110 Memorandum from Acting Sales Superintendent in Birmingham, 17 November 1938. BTA, TCB 2/171-2/172.

111 Letter from Mr Mousley to the District Manager, 20 April 1938. BTA, TCB 2/ $171-2 / 172$.

112 Letter from the Traffic Superintendent, April 1938. BTA, TCB 2/171-2/172.

113 Scully, 'From "She Would Say That, Wouldn't She?".

114 McGuire and Carel, 'Stigma, Technology and Masking'.

115 The letterhead on the Charles Winn \& Co. stationery also indicates that Mr Arthur Mousley held an MBE.

116 Kerridge, 'Aids for the Deaf'. 
117 Ibid.

118 Ibid.

119 Gooday and Sayer, Managing the Experience of Hearing Loss.

120 'Suggestion that a flat mouthpiece, instead of the normal cupped one, should be provided to facilitate the use of a telephone in conjunction with a deaf aid worn on the chest'. Letter from W. S. Clark to Telephone Headquarters, 20 March 1954. BTA, TCB 2/172, folder 'Telephones for Deaf People'.

121 Ibid.

122 Ibid.

123 Agar, Constant Touch, p. 64.

124 Kay, 'Inventing Telephone Usage', pp. 150-180.

125 Sterling, B., 'The Hacker Crackdown: Evolution of the US Telephone Network', in N. W. Heap (ed.), Information Technology and Society (London: Sage, 1995), pp. 33-40, p. 37.

126 George, G. F., 'The Federal Communications Commission and the Bell System: Abdication of Regulatory Responsibility', Indiana Law Journal, 44:3 (1969), 459-477, pp. 460-462. I am grateful to Mara Mills for drawing this case to my attention.

127 This struggle has been documented in Lang, H. G., A Phone of Our Own: The Deaf Insurrection against Ma Bell (Washington, DC: Gallaudet University Press, 2000). This book also repeatedly emphasises the difficulty of working with the British Post Office.

128 Mills, 'Deafening', p. 132.

129 Ibid., p. 120.

130 Ibid.

131 Noble, W. G., Assessment of Impaired Hearing: A Critique and New Method (New York: Academic Press, 1978).

132 Mills, 'Deafening', p. 121.

133 Ibid., pp. 118-143.

134 Virdi and McGuire, 'Phyllis M. Tookey Kerridge'.

135 Blume, S., The Artificial Ear: Cochlear Implants and the Culture of Deafness (London: Rutgers University Press, 2010).

136 For example, see Blume, The Artificial Ear and Virdi, J., 'Between Cure and Prosthetic: "Good Fit" in Artificial Eardrums', in C. Jones (ed.), Rethinking Modern Prostheses in Anglo-American Commodity Cultures, 1820-1939 (Manchester: Manchester University Press, 2017), pp. 48-69.

137 Wyatt, S., 'Non-Users Also Matter: The Construction of Users and Non-Users of the Internet', in T. Pinch and N. Oudshoorn (eds), How Users Matter: The Co-Construction of Users and Technology (Cambridge, MA: MIT Press, 2005), pp. 67-79, p. 76. 